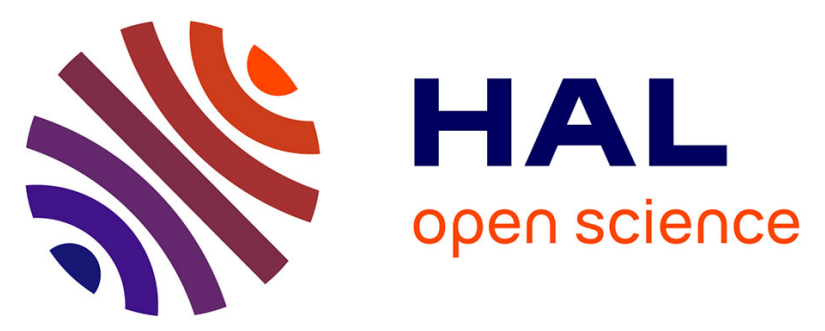

\title{
Tight-Binding Inhibition of Human Monoamine Oxidase B by Chromone Analogs: A Kinetic, Crystallographic, and Biological Analysis
}

Joana Reis, Nicola Manzella, Fernando Cagide, Jeanne Mialet-Perez, Eugenio Uriarte, Angelo Parini, Andrea Mattevi, Fernanda Borges, Claudia Binda

\section{To cite this version:}

Joana Reis, Nicola Manzella, Fernando Cagide, Jeanne Mialet-Perez, Eugenio Uriarte, et al.. TightBinding Inhibition of Human Monoamine Oxidase B by Chromone Analogs: A Kinetic, Crystallographic, and Biological Analysis. Journal of Medicinal Chemistry, 2018, 61 (9), pp.4203-4212. 10.1021/acs.jmedchem.8b00357 . inserm-02446027

\section{HAL Id: inserm-02446027 https://www.hal.inserm.fr/inserm-02446027}

Submitted on 20 Jan 2020

HAL is a multi-disciplinary open access archive for the deposit and dissemination of scientific research documents, whether they are published or not. The documents may come from teaching and research institutions in France or abroad, or from public or private research centers.
L'archive ouverte pluridisciplinaire HAL, est destinée au dépôt et à la diffusion de documents scientifiques de niveau recherche, publiés ou non, émanant des établissements d'enseignement et de recherche français ou étrangers, des laboratoires publics ou privés. 


\title{
Tight-binding inhibition of human monoamine
}

\author{
oxidase B by chromone analogs: a kinetic,
}

crystallographic and biological analysis

Joana Reis ${ }^{\dagger}$, Nicola Manzella ${ }^{\dagger}$,Fernando Cagide ${ }^{\dagger}$, Jeanne Mialez-Perez ${ }^{*}$, Eugenio

Uriarte $^{\S, \|}$, Angelo Parini ${ }^{*}$, Andrea Mattevi ${ }^{\ddagger}$, Fernanda Borges ${ }^{\dagger}$, Claudia Binda ${ }^{¥, *}$

${ }^{\dagger}$ CIQUP/Department of Chemistry and Biochemistry, University of Porto, Portugal

Institute of Metabolic and Cardiovascular Diseases (I2MC), Institut National de la Santé et de la Recherche Médicale (INSERM), Université de Toulouse, Toulouse,

France

${ }^{\S}$ Departamento de Química Orgánica, Facultad de Farmacia, Universidad de Santiago de Compostela, 15782 Santiago de Compostela, Spain

"Applied Chemical Science Institute, Universidad Autonoma de Chile, 7500912 Santiago de Chile, Chile

${ }^{¥}$ Department of Biology and Biotechnology, University of Pavia, Italy 


\section{ABSTRACT (about 150 words)}

Monoamine oxidase B (MAO-B) is a validated drug target for Parkinson's disease. Chromone derivatives were identified as novel potent and reversible MAO-B inhibitors and herewith we report on a crystallographic and biochemical analysis to investigate their inhibition mechanism. The crystal structures of human MAO-B in complex with three chromone analogs bearing different substituents on the exocyclic aromatic ring (determined at 1.6-1.8 A resolution) showed that they all bind in the active site cavity of the protein with the chromone moiety located in front of the FAD cofactor. These inhibitors form two hydrogen bonds with Tyr435 and Cys172 and perfectly fit the hydrophobic flat active site of human MAO-B. This is reflected in their tight-binding mechanism of inhibition with $K_{i}$ values of 55,17 and $31 \mathrm{nM}$ for $N-\left(3^{\prime}, 4^{\prime}-\right.$ dimethylphenyl)-4-oxo-4H-chromene-3-carboxamide (1), $\mathrm{N}$-(3'-chlorophenyl)-4-oxo4H-chromene-3-carboxamide (2) and $N$-(3'-fluorophenyl)-4-oxo-4H-chromene-3carboxamide (3), respectively. These compounds were also 1000-fold more effective in reducing the cellular levels of reactive oxygen species (ROS) in comparison to $L$ deprenyl. 


\section{Introduction}

Monoamine oxidases (MAOs, EC 1.4.3.4) are broadly distributed enzymes that contain a flavin adenine dinucleotide (FAD) cofactor covalently bound to a cysteine residue. They are expressed in several living organisms and two isoforms are present in mammals, namely MAO-A and MAO-B, which are responsible for the major neurotransmitter metabolism in both the central nervous system (CNS) and peripheral tissues. ${ }^{1,2}$ Both isoenzymes are bound to the outer mitochondrial membrane and catalyze the oxidative deamination of aromatic amine substrates (Figure 1).<smiles>[NH3+]CCc1ccc(O)c(O)c1</smiles>

Dopamine

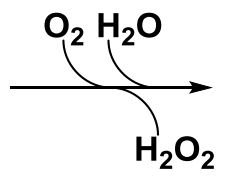

Dopanal

Figure 1. Scheme of the FAD-dependent oxidative reaction catalyzed by MAOs. Dopamine is showed as substrate that is preferentially metabolized by MAO-B in the CNS. Besides the aldehyde product (dopanal) and ammonia derived from substrate oxidation, hydrogen peroxide is also generated upon cofactor re-oxidation by molecular oxygen.

MAO-A and MAO-B display different substrate specificity that depends on the tissue distribution of these enzymes. Serotonin and catecholamines are preferentially metabolized by MAO-A, whereas dopamine and phenethylamine are mainly metabolized by MAO-B. In light of their key role in neurotransmitter metabolism in the brain, these enzymes are validated drug targets for neurological diseases. MAO inhibitors are currently used in the clinical practice for the treatment of depression and Parkinson's disease. Most of them, such as tranylcypromine and rasagiline, irreversibly inactivate the enzyme by forming a covalent adduct with the flavin cofactor. More 
recently, safinamide, a MAO-B selective and reversible inhibitor, was newly approved in Europe and United States as Xadago ${ }^{\circledR}$ as adjunct therapy for Parkinson's disease. ${ }^{3}$ Additionally, the expression of MAO-B in neuronal tissues increases 4-fold with aging, resulting in an intensification of dopamine metabolism and higher production of hydrogen peroxide. ${ }^{4}$ Indeed, in the clinical treatment of Parkinson's disease MAO-B inhibition is thought to be beneficial both in restoring physiological levels of dopamine and in exerting a neuroprotective effect by preventing the production of excessive hydrogen peroxide (Figure 1). ${ }^{4}$ This aspect is emerging as a relevant issue also in the context of MAO activity and reactive oxygen species (ROS) in non-neuronal tissues including heart, ${ }^{5}$ prostate $^{6}{ }^{6}$ and adipose macrophages. ${ }^{7}$

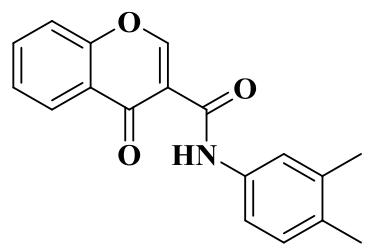

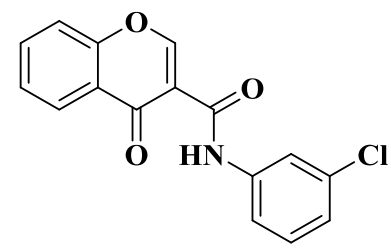

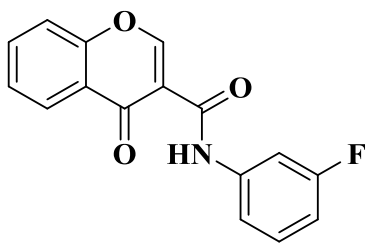

3<smiles>O=c1c(CNc2cccc(Cl)c2)coc2ccccc12</smiles>

4

Figure 2. Chemical structures of MAO-B inhibitors based on the chromone scaffold.

Chromones (4H-benzopyran-4-one), a class of heterocyclic compounds largely distributed in nature, have attracted attention in the field of drug discovery due to their interesting biological activities (Figure 2). ${ }^{8,9}$ Moreover, several studies have shown that chromone is a privileged structure for the rational discovery and development of new MAO-B inhibitors. ${ }^{10-13}$ Inhibition studies performed with microsomal recombinant human MAO-B showed that a series of chromone analogs selectively and reversibly bind to this enzyme with $\mathrm{IC}_{50}$ values in sub-nanomolar range. ${ }^{13}$ Preliminary kinetic studies demonstrated that compound $\mathbf{1}$ acted as a competitive MAO-B inhibitor while 
compound 2 displayed a non-competitive profile. $^{13}$ Despite several computational docking studies to predict chromone binding to MAOs, ${ }^{10,13,14}$ no experimental structural information was available so far. In order to clarify the MAO-B inhibition mechanism of this class of compounds, we undertook a crystallographic analysis combined with a more in-depth kinetic characterization using purified recombinant human MAO-B. Moreover, in light of the recent findings highlighting the role of MAOderived ROS in several cellular processes, we have also evaluated the biological activity of these compounds in reducing the cellular ROS levels in HEK-293 cells.

\section{Results and discussion}

\section{Chemistry}

Compounds 1 and $\mathbf{2}$ (Figure 2) were previously synthesized in moderate yields through the in situ generation of an acyl chloride intermediate, using phosphoryl chloride $\left(\mathrm{POCl}_{3}\right)$ in $N, N$-dimethylformamide (DMF), and the subsequent addition of the appropriate arylamine, as reported by Reis et al. ${ }^{13}$ Likewise, compound $\mathbf{3}$ was synthesized from chromone 3-carboxylic acid in an amidation reaction using $\mathrm{POCl}_{3}$ (Scheme 1).<smiles>O=C(O)c1coc2ccccc2c1=O</smiles><smiles>C</smiles><smiles>O=C(Nc1cccc(F)c1)c1coc2ccccc2c1=O</smiles>

3

Scheme 1 - Strategy followed for the synthesis of chromone-3-phenylcarboxamide derivative $\mathbf{3}$, from chromone 3-carboxylic acid. Reagents and conditions: $\mathrm{POCl}_{3}$, DMF, 3-fluoroaniline, r.t., 5h. 
Compound 4 was obtained by a reductive amination, in the presence of sodium triacetoxyborohydride, of the imine intermediate formed from the reaction of 3formylchromone with 3-chloroaniline (Scheme 2).<smiles>O=Cc1coc2ccccc2c1=O</smiles><smiles>[13CH3]</smiles>

3-formylchromone<smiles>O=c1c(CNc2cccc(Cl)c2)coc2ccccc12</smiles>

4

Scheme 2 - Synthetic strategy followed for the synthesis of chromone derivative 4 from 3formylchromone. Reagents and conditions: 3-chloroaniline, $\mathrm{Na}(\mathrm{AcO})_{3} \mathrm{BH}$, r.t., $15 \mathrm{~min}$.

\section{Structures of human MAO-B in complex with chromone inhibitors}

The crystal structures of human MAO-B in complex with inhibitors $\mathbf{1}, \mathbf{2}$ and $\mathbf{3}$ were solved at 1.8, 1.6 and $1.7 \AA$ resolution, respectively. Crystallographic statistics are reported in Table 1. The unbiased electron density map was of extraordinary good quality, which allowed to unambiguously model the inhibitor molecules in the enzyme active site. For all three structures, no relevant differences in inhibitor binding and active site conformation were found between the two molecules present in the asymmetric unit (rmsd for the $\mathrm{C}_{\alpha}$ atoms are $0.28,0.23$ and $0.22 \AA$ between monomers $\mathrm{A}$ and $\mathrm{B}$ for the structures in complex with compounds 1, $\mathbf{2}$ and 3, respectively). Hereafter we will refer to subunit A of each structure for the following discussion. 
(a)

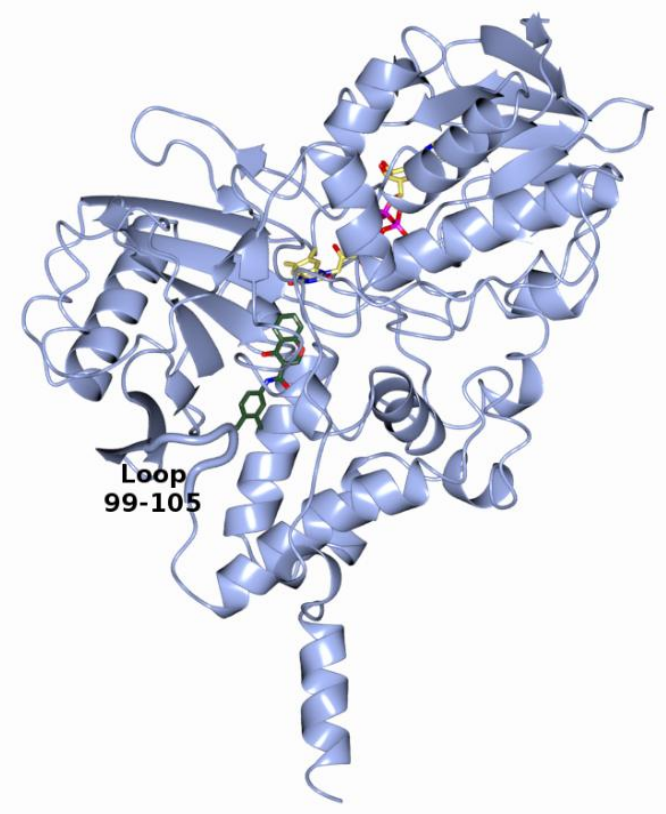

(b)

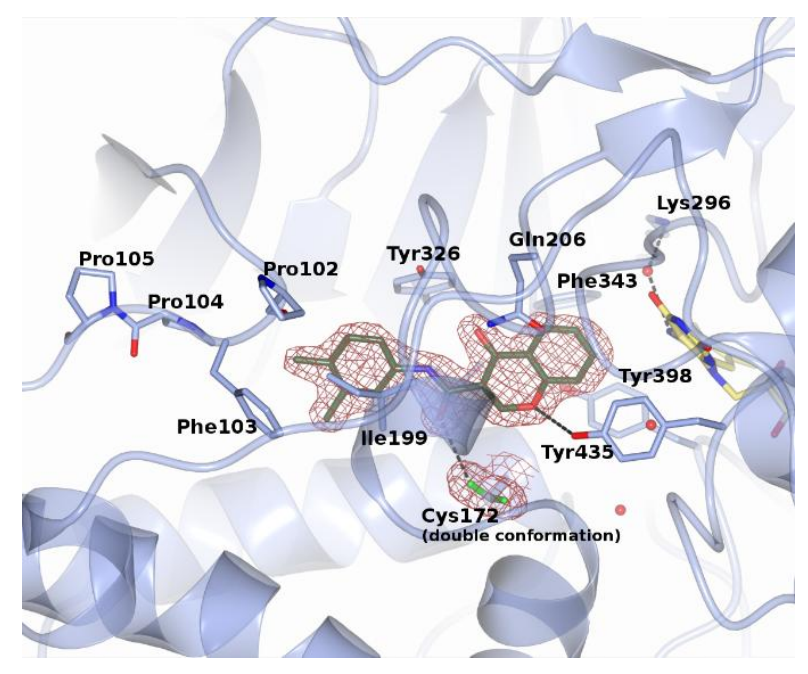

(c)

(d)

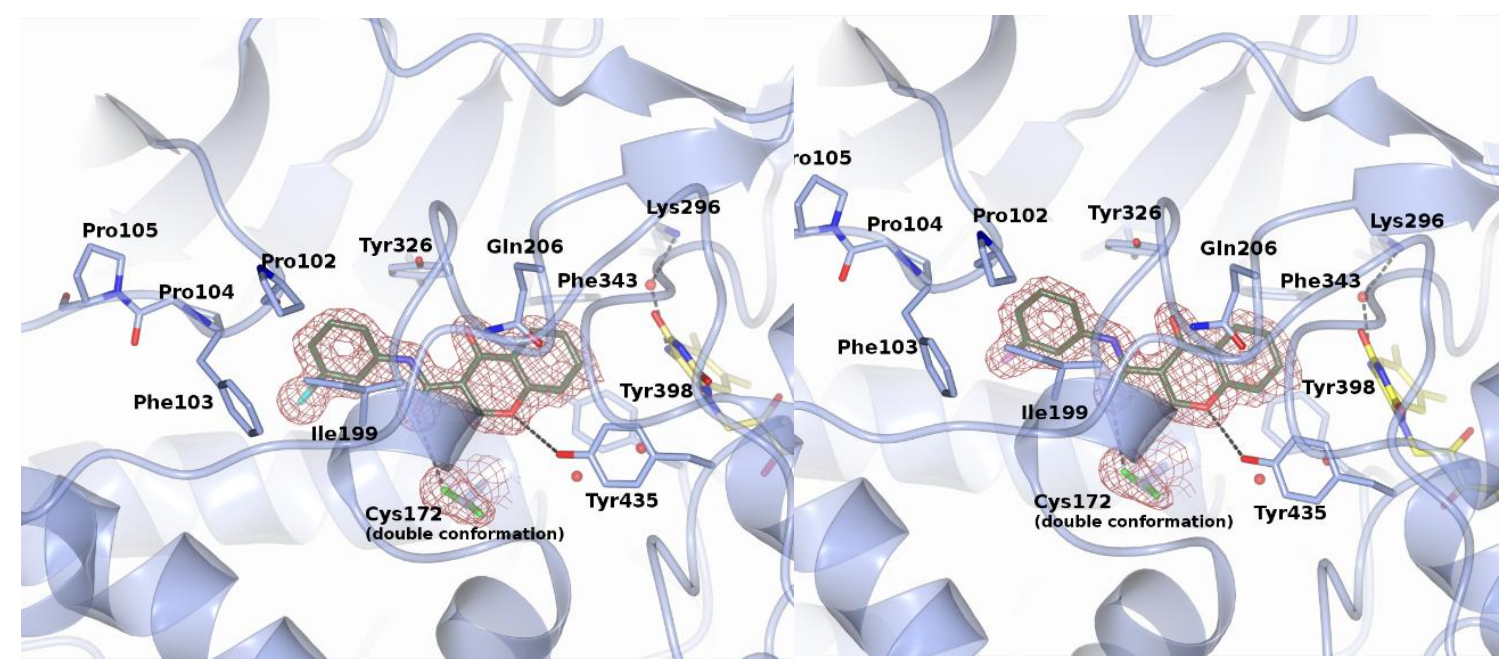

Figure 3. Crystal structure of human MAO-B in complex with chromone inhibitors. (a) Overall ribbon diagram (ice blue) of human MAO-B structure oriented with the membrane-bound C-terminal helix pointing at the bottom of the figure. The loop formed by residues 99-105 that admits to the enzyme active site is highlighted in bold style. The FAD cofactor is in stick representation with carbon, nitrogen, oxygen and phosphorus atoms colored in yellow, blue, red and magenta, respectively. Inhibitor $\mathbf{1}$ is showed as reference of chromone analogs binding mode with atom color code as FAD except for carbons that are in dark green. (b) Zoomed view of human MAO-B active site in complex with inhibitor $\mathbf{1}$. The orientation of the molecule is rotated approximately $45^{\circ}$ around an axis perpendicular to the figure plane with respect 
to Figure 3a. Residues lining the enzyme active site are depicted as sticks with carbon atoms in ice blue (sulphur atoms in green). Hydrogen bonds are drawn as dashed lines. Water molecules are represented as red spheres. The refined $2 \mathrm{Fo}-\mathrm{Fc}$ electron density map contoured at $1.2 \sigma$ is showed in dark red for the inhibitor molecule and for Cys172 in double conformation. (c) Zoomed view of human MAO-B active site in complex with inhibitor 2 . Orientation and color code is as in Figure $3 b$ (chlorine atom in cyan). (d) Zoomed view of human MAO-B active site in complex with inhibitor 3. Orientation and color code is as in Figure $3 b$ (fluorine atom in pink).

All chromone analogs clearly bind in the hydrophobic active site of human MAO-B ${ }^{1}$ (Figure 3a). In particular, the 1,4-benzopyrone moiety occupies the substrate-binding site in front of the flavin ring, whereas the amide linker and the differently-substituted exocyclic ring moieties extend into the entrance space whose access is negotiated by loop 99-105 (Figures 3a, 3b, 3c, 3d). The pyrone carbonyl group points towards the upper part of the active site whereas the oxygen atom of the ring is located in the more hydrophilic part of the cavity and establishes a weak hydrogen bond with Tyr435 (about $3.4 \AA$ in all structures). This binding mode is in agreement with previous docking studies ${ }^{11,14}$ except for a hydrogen bond predicted to exist between the pyrone carbonyl group and Tyr326 that instead is not observed.

The amide linker of all three inhibitors lies nearby the gating residue Ile199 that is in the open conformation similarly to other human MAO-B structures in complex with bulky inhibitors. ${ }^{1,15}$ The carbonyl group of the linker is H-bonded to Cys172 with distances ranging from 3.2 to $3.4 \AA$ (Figures $3 \mathrm{~b}, 3 \mathrm{c}, 3 \mathrm{~d}$ ), which was also predicted by previous docking studies and which is fully consistent with the longer hydrogen bonds that are known to involve sulphur atoms. ${ }^{16}$ Interestingly, careful inspection of the electron density showed that the side chain of Cys172 exists in a double conformation (Figures 3b, 3c, 3d) and by using the program PHENIX $^{17}$ we refined the occupancy 
values for the two rotamers of Cys 172 in each of the three structures. This resulted to be 0.5 in the case of the complex with inhibitor $\mathbf{1}$, whereas for the structures with $\mathbf{2}$ and $\mathbf{3}$ the conformation H-bonded with the inhibitor was preferred with respect to the other one (occupancy is about 0.7 versus 0.3 of the other rotamer; Figures $3 \mathrm{c}$ and $3 \mathrm{~d}$ ). Interestingly, the cysteine rotamer that is H-bonded with the chromone linker moiety is the conformation normally present in other human MAO-B structures (Figure 4). Nevertheless, Cys 172 double conformation was previously observed in the structures of human MAO-B in complex with the slow substrate $p-\mathrm{NO}_{2}$-benzylamine ${ }^{18}$ and in complex with a rasagiline analog bearing an $\mathrm{OH}$ substituent on the aminoindan ring. ${ }^{18,19}$ In both cases, one of the two Cys172 rotamers forms a hydrogen bond with the oxygen atom of the ligand, similarly to that formed with the carbonyl group of the chromone inhibitors. These observations suggest that the involvement of Cys172 in hydrogen bond formation as well as its flexibility in adopting a double conformation, though rarely found in other MAO-B crystal structures, ${ }^{1}$ is not exclusive to the complexes with chromones and might be relevant to stabilize binding of some inhibitors.

The differently-substituted aromatic ring linked to the chromone unit through the amide spacer represents the varying moiety of the inhibitors under study (Figure 2). In all structures the substituted exocyclic ring binds in the entrance space of MAO-B active site with the halogen atom of $\mathbf{2}$ and $\mathbf{3}$ occupying the same position as one of the two methyl groups of compound 1 (Figure 4). No differences in the active site architecture were found between $\mathbf{2}$ and $\mathbf{3}$, indicating that the halogen atomic radius does not affect inhibitor binding. Interestingly, structure superposition with MAO-B in complex with safinamide (Figure 4) and coumarin analogs ${ }^{15}$ showed that their halogen substituents perfectly overlaps with those of $\mathbf{2}$ and $\mathbf{3}$ (Figure 4) suggesting that this part of the active 
site may represent a subsite favorable for halogen binding. A direct comparison between coumarin and chromone inhibitors is not applicable as different drug design strategies were undertaken, with the spacer-phenyl chain added to the aromatic part of coumarin rather than to the pyrone ring as in the case of chromone analogs.

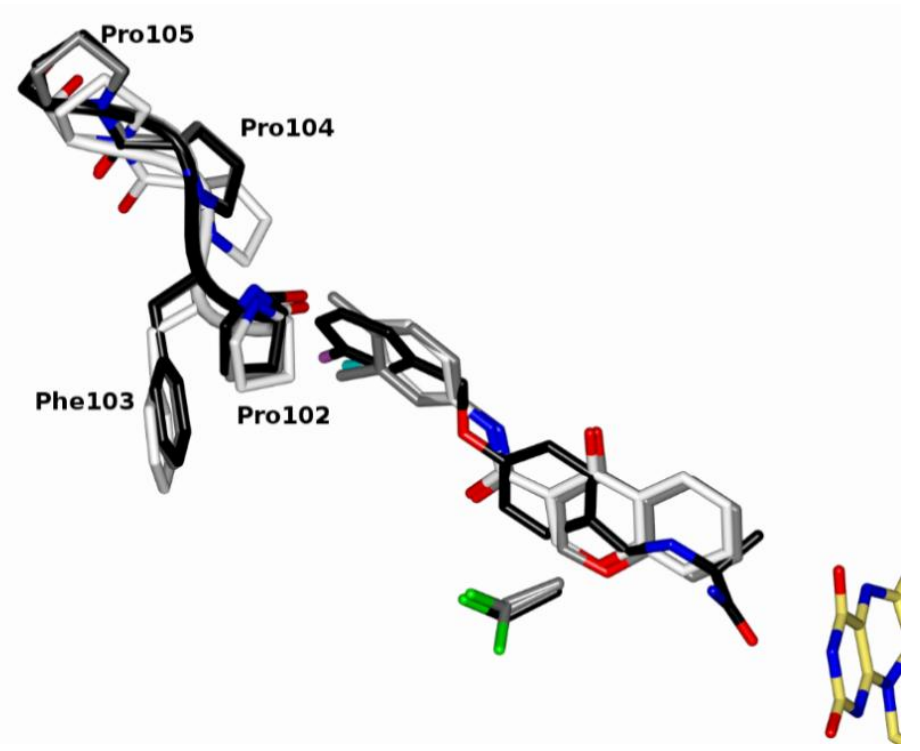

Figure 4. Structural superposition between structures of human MAO-B in complex with inhibitor 1, inhibitor 2 and safinamide ${ }^{15}$ (PDB code 2V5Z) depicted with carbon atoms in gray, white and black, respectively (inhibitor $\mathbf{3}$, whose fluorine-substituted aromatic ring perfectly overlaps with that of $\mathbf{2}$, was omitted for clarity). Color code for FAD and the other atoms is as in Figure 3.

This comparative analysis also highlighted another aspect related to loop 99-105 whose flexibility allows the admission of ligands into the enzyme active site (Figure 3a). ${ }^{1}$ In particular, Pro102 and Phe103 were previously found to adopt different conformations depending on the size of the bound inhibitor, as observed also in the structures in complex with chromone analogs described in this study (Figure 4). Nevertheless, in the case of compounds 2 and 3 , we observed a shift of about $1.5 \AA$ in the position of Pro104-Pro105 towards the inhibitor, which was not found in any other MAO-B structure including that in complex with $\mathbf{1}$. This conformation is probably due to the fact 
that the halogenated chromone analogs do not extend as long as safinamide and lack the second substituent on the aromatic ring as it happens in $\mathbf{1}$ (Figure 4). However, as this conformational difference is moderate and does not correlate with binding affinity of chromone analogs, this aspect is not worth further discussion.

An important feature in the conformation of all chromone analogs bound to human MAO-B active site is the intramolecular hydrogen bond between the carbonyl group of the pyrone ring and the nitrogen atom of the spacer (about $2.7 \AA$ in all three structures; not shown in Figures 3b, 3c, 3d). This interaction was found also in the crystallographic structure of chromone compounds ${ }^{12}$ and it is conserved when bound to the enzyme active site. The human MAO-B active site cavity, with its flat and elongated shape, ${ }^{1}$ provides an ideal niche for this class of molecules, which may be related to their inhibition mechanism as described below.

\section{Inhibition studies on chromone analogs}

As the crystallographic analysis demonstrated that all chromone inhibitors bind in the MAO-B active site in a highly conserved way, we carried out a more in-depth biochemical characterization to clarify their inhibition mechanism. For this task, we

used a fluorimetric horseradish peroxidase-Amplex Red-coupled assay ${ }^{20}$ using a purified sample of recombinant human MAO-B and benzylamine as substrate. Initial velocity data measured at varying substrate and inhibitor concentrations were fitted to the appropriate form of the Michaelis-Menten equation (using GraphPad Prism software 5.0) which gave the best graphical fitting to the curves with a $\mathrm{R}^{2}$ value proximal to 1.0. Moreover, in order to gain a better visual assessment of enzyme inhibition, data were also analysed using a linear double-reciprocal plot. In the case of inhibitor $\mathbf{1}$, the 
nonlinear regression analysis gave the best fitting with the equation corresponding to a mixed type inhibition mechanism with a $K_{i}=0.31 \pm 0.08 \mathrm{nM}(\alpha=25.90)$ (Figure 5a, left panel). Indeed, in the double-reciprocal plot data were fitted to lines intersecting in the upper-left quadrant (Figure 5a, right panel), indicating that this compound acted as a mixed-type inhibitor towards human MAO-B. Instead, chromone 2 clearly showed a non-competitive inhibition profile $\left(K_{\mathrm{i}}=7.5 \pm 1.2 \mathrm{nM}\right)$ by both Michaelis-Menten equation fitting and linear regression plot analysis (Figure 5b). These data are in agreement with the previous studies performed with the microsomal enzyme and reveal that, independently from the substituent on the aromatic ring, these chromone analogs seemingly fail to feature a competitive mechanism of inhibition.

(a)
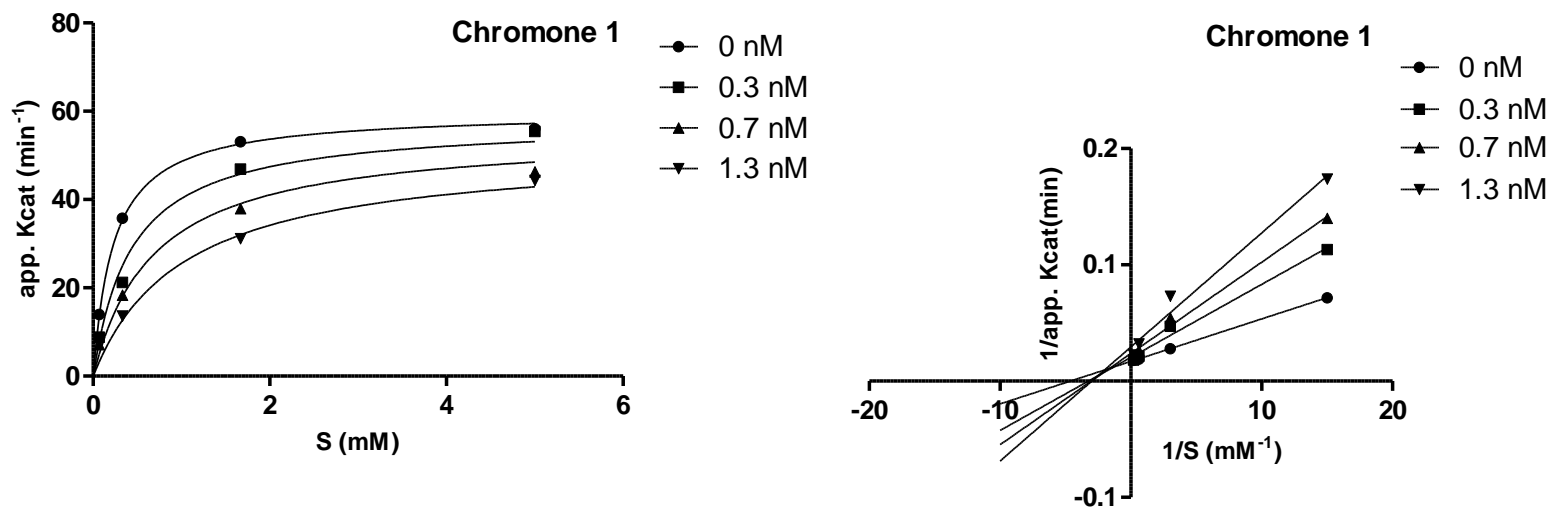

(b)
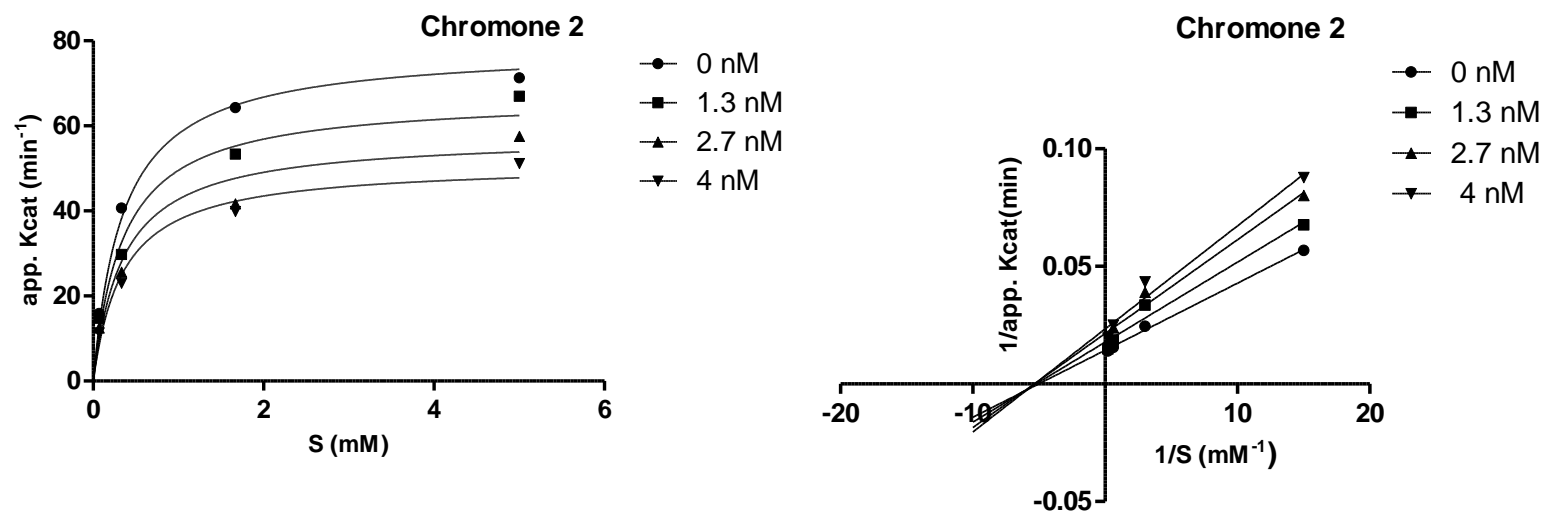
Figure 5 - Kinetic studies on the mechanism of human MAO-B inhibition by chromones $\mathbf{1}$ (a) and 2 (b). The effect of the inhibitors on the enzyme was determined using both the nonlinear regression on GraphPad Prism software 5.0 (left panels) and the double reciprocal plot analysis (right panels). Apparent $\mathrm{k}_{\mathrm{cat}}\left(\mathrm{y}\right.$ axis) were calculated as $\mathrm{v}_{0} /[\mathrm{MAO}-\mathrm{B}]$.

It is well-known that this mixed or non-competitive behaviour might occur when ligands bind to the enzyme active site in a way that is defined as "tight-binding inhibition". ${ }^{20}$ In this case the standard steady-state kinetic model used to describe the mechanism of inhibition is no longer valid and the resulting double-reciprocal plots appear similar to the classical pattern for non-competitive inhibitors. To test whether this may hold for the chromone analogs, we applied a protocol by plotting the $\mathrm{IC}_{50}$ values for each chromone analog determined at different substrate concentrations, ${ }^{21}$ using the same fluorimetric assay employed for the classical steady-state experiments. In the case of tight-binding inhibitors, higher concentrations of substrate are needed in order to compete with the inhibitor in binding to the enzyme active site. With both 1 (not shown) and 2 (Figure 6), a linear correlation between $\mathrm{IC}_{50}$ values and substrate concentration was observed, in full agreement with tight-binding competitive inhibition. $^{21}$

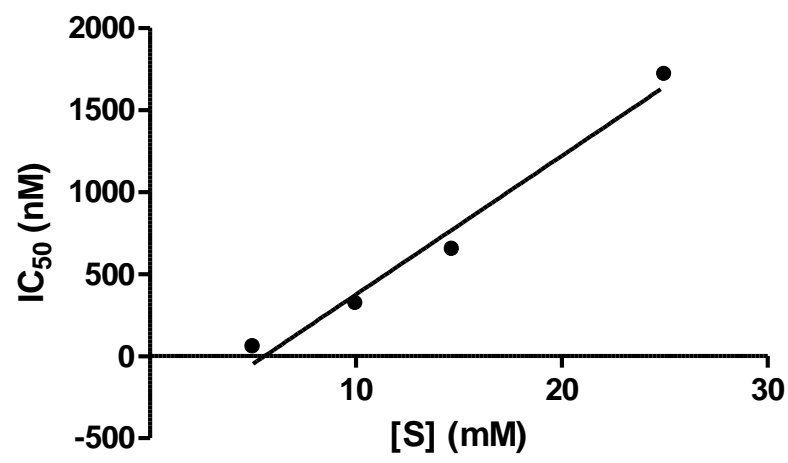

Figure 6. Effects of substrate $(\mathrm{S})$ concentration on the $\mathrm{IC}_{50}$ values for chromone 2. A similar pattern was obtained for chromone $\mathbf{1}$ (not shown). 
After having assessed that chromone analogs, independently from the type of substituent present on the aromatic ring, feature a tight-binding inhibition mechanism, the next step was to determine an accurate value of inhibition constants. This was accomplished by following published protocols, ${ }^{21,}{ }^{22}$ which use the Morrison equation (Eq. 1), to describe the fractional velocity of an enzymatic reaction as a function of inhibitor concentration, at fixed concentrations of enzyme and substrate:

$$
\frac{v_{i}}{v_{0}}=1-\frac{\left([E]+[I]+K_{i}^{a p p}\right)-\sqrt{\left([E]+[I]+K_{i}^{a p p}\right)^{2}-4[E][I]}}{2[E]}
$$

where $\mathrm{v}_{\mathrm{i}} / \mathrm{v}_{0}$ represents the enzyme activity, whereas [E] is the total enzyme concentration, [I] is the total inhibitor concentration, and $K_{\mathrm{i}}^{\text {app }}$ is the apparent inhibition constant. The real inhibition constant $\left(K_{\mathrm{i}}\right)$ is obtained using a different equation in accordance with the inhibitor type. In the case of a competitive tight-binding inhibitor, this is achieved through Eq. 2:

$$
K_{i}^{a p p}=K_{i}\left(1+\frac{[S]}{K_{m}}\right)
$$

Accordingly, we used the fluorimetric Amplex Red assay to obtain the data that were plotted in a dose-response curve described by the Morrison equation for both chromone 1 (Figure 7a) and chromone 2 (Figure 7b). By using Eq. 2, the tight-binding $K_{i}$ values for the inhibitors were determined to be $55 \pm 9 \mathrm{nM}$ and $17 \pm 2 \mathrm{nM}$ for $\mathbf{1}$ and 2 , respectively. 
(a)

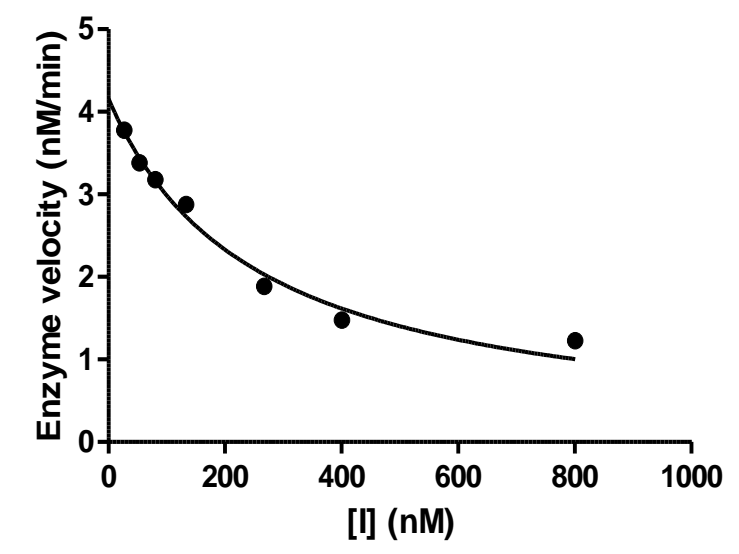

(b)

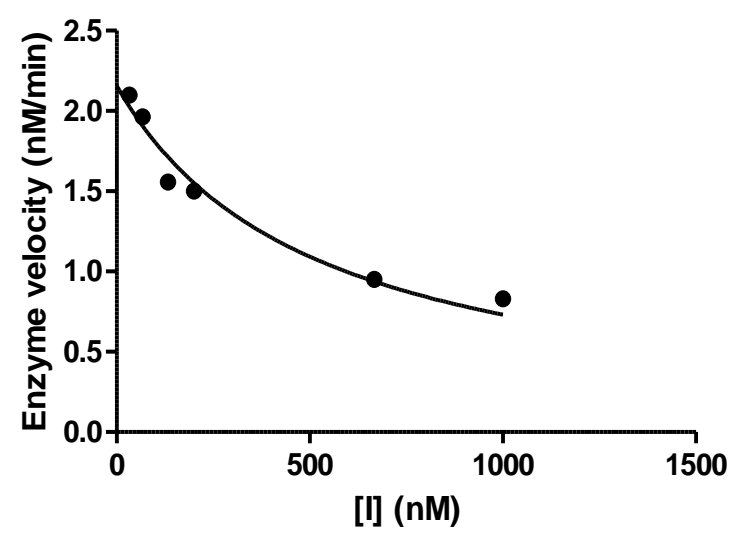

Figure 7. Plot of enzyme velocity as a function of inhibitor (I) concentration for chromone $\mathbf{1}$ (a) and chromone 2 (b). The solid curve drawn through the data points represents the best fit to the Morrison equation.

Based on these results, we extended the kinetic analysis to other chromone analogs to probe both the type of halogen substituent on the exocyclic phenyl ring and the importance of the carbonyl group on the amide spacer (forming the hydrogen bond with Cys 172) in enhancing binding affinity. For the former task, inhibitor $\mathbf{3}$ bearing a fluorine group (Figure 2) and its bromine analog $\mathrm{N}$-(3-bromophenyl)-4-oxo- $4 \mathrm{H}$ chromene-3-carboxamide $^{13}$ were tested for their binding mechanism using the procedures described above for $\mathbf{1}$ and $\mathbf{2}$. Both $\mathbf{3}$ and the bromine analog showed a tightbinding profile with the nonlinear regression curves and double-reciprocal plots displaying a mixed and a non-competitive type of inhibition, respectively (data not shown). Accordingly, the tight-binding inhibition $K_{i}$ values were determined by doseresponse curve analysis (Figures $8 \mathrm{a}$ and $8 \mathrm{~b}$ ), which resulted to be $31 \pm 2 \mathrm{nM}$ for compound 3 and $27 \pm 2 \mathrm{nM}$ for $N$-(3-bromophenyl)-4-oxo-4H-chromene-3carboxamide. This indicates that all chromone analogs bearing a different halogen substituent in meta position of the aromatic ring bind to human MAO-B with similar 
affinity, which nevertheless was found also when two methyl groups are present (chromone 1).

(a)

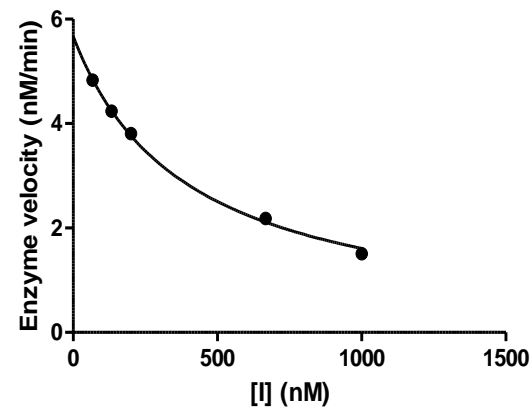

(b)

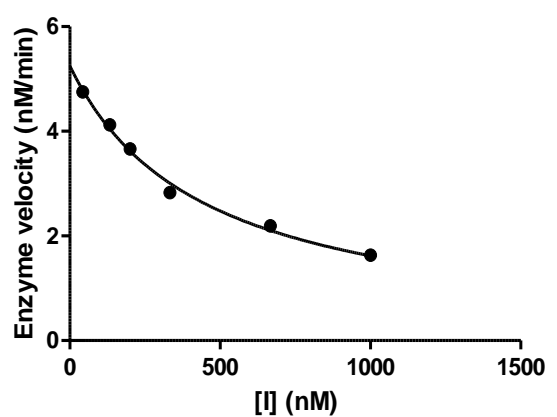

(c)

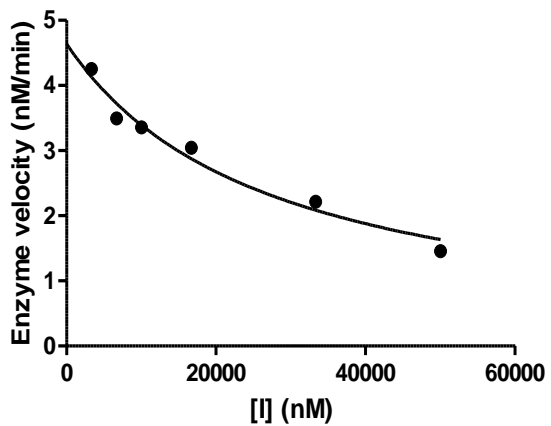

Figure 8. Plot of enzyme velocity as a function of inhibitor (I) concentration for N-(3-bromophenyl)-4oxo-4H-chromene-3-carboxamide (a), chromone 3 (b) and chromone 4 (c). The solid curve drawn through the data points represents the best fit to the Morrison equation.

To investigate the role of the amide spacer and its interaction with Cys172, a chromone analog bearing a chlorine group in meta position but lacking the carbonyl group in the linker moiety (chromone 4, Figure 2), was synthesized and used for both kinetic and crystallographic analysis. Even though we could still observe a tight-binding inhibition profile, chromone 4 acted as a competitive inhibitor with a $K_{i}$ of $2927 \pm 488 \mathrm{nM}$, i.e. about 100-fold higher than that of the other chromone analogs. This suggests that, although the chromone scaffold is likely to trigger the tight-binding inhibition mechanism of these compounds, the hydrogen bond between the amide carbonyl group and Cys172 observed in the crystal structures (Figures 3b, 3c, 3d) is relevant for binding affinity. To confirm this hypothesis we attempted to determine the structure of human MAO-B in complex with chromone 4. Although X-ray data could be collected at $2.0 \AA$ resolution, the electron density map for the inhibitor was of very bad quality, which 
hampered modelling of the molecule in the enzyme active site. However, we cannot rule out the hypothesis that the lower rigidity of chromone 4 determined by the absence of the planar amide spacer may give a significant contribution to destabilize inhibitor binding in the active site. Indeed, previous studies showed that analogs bearing a spacer with the carbonyl group but with either a sulphur or an oxygen atom in place of the NH group (i.e. lacking the full planar amide conformation and therefore featuring a lower rigidity) displayed higher $\mathrm{IC}_{50}$ values. ${ }^{13}$ Nevertheless, those analogs are expected to lack the intramolecular hydrogen bond that instead in $\mathbf{4}$ is likely to exist and confer a good level of rigidity to the molecule. Therefore, the hydrogen bond between chromone analogs and Cys172 may significantly contribute to the high binding affinity of $\mathbf{1 , 2}$ and 3 inhibitors.

\section{Biological evaluation of ROS production assay}

On the basis of their potent effect in inhibiting recombinant human MAO-B, we next carried out a biological evaluation of chromones $\mathbf{1}$ and $\mathbf{2}$ on ROS production in HEK293 cells transfected with human MAO-B and stimulated with the substrate tyramine. As shown in Figure 9, incubation of MAO-B-transfected cells with tyramine for $15 \mathrm{~min}$ induced ROS production, measured with DCFDA fluorescence. The specific involvement of MAO-B in ROS generation was supported by the complete prevention of DFCDA production by the MAO-B inhibitor L-deprenyl. As observed with Ldeprenyl, pre-incubation of the cells with compounds $\mathbf{1}$ or $\mathbf{2}$ dose-dependently inhibited ROS production following tyramine addition (Figure 9). Remarkably, both $\mathbf{1}$ and $\mathbf{2}$ were 1000 fold more potent than L-deprenyl for inhibition of ROS production by MAO B in HEK-293 cells. 

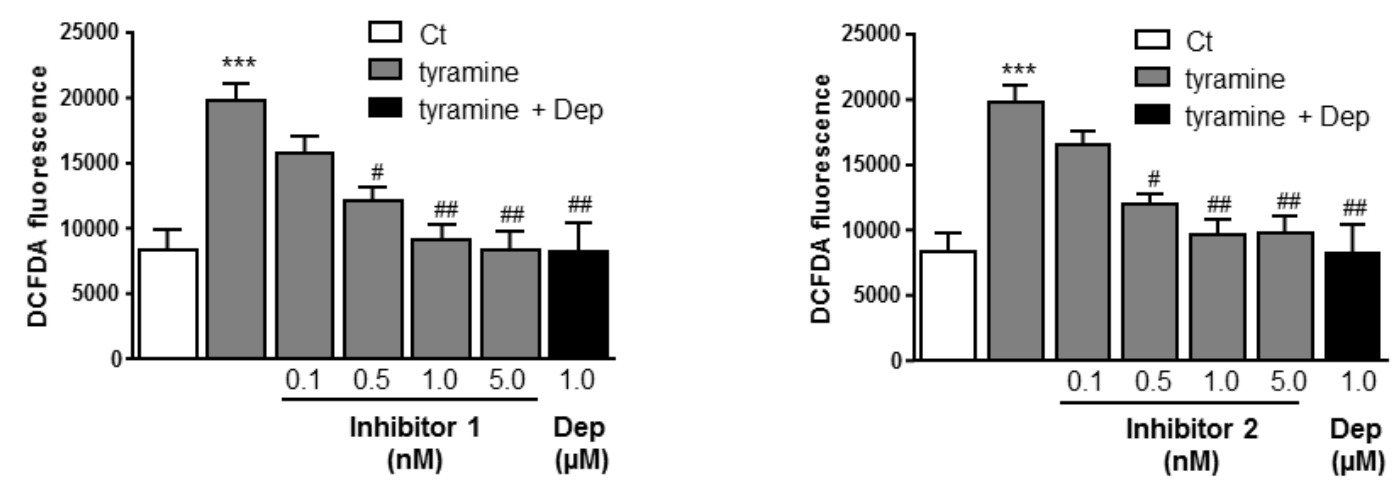

Figure 9. Cellular inhibition of ROS production by inhibitors 1 and 2. HEK-293 cells transfected with MAO-B were incubated with tyramine for $15 \mathrm{~min}$ and intracellular ROS generation was measured with the fluorescent probe DCFDA. Pre-incubation with L-deprenyl (Dep, $1 \mu \mathrm{M})$ or compounds 1 or 2 was performed $10 \mathrm{~min}$ before addition of tyramine. Results are the mean +/- s.e.m. of 4 experiments. $* * * \mathrm{p}<0.001$ for $\mathrm{Ct}$ vs tyramine; ${ }^{*} \mathrm{p}<0.01,{ }^{* *} \mathrm{p}<0.001$ for tyramine vs tyramine + inhibitors, Anova postTukey's statistical analysis.

\section{Conclusion}

A series of chromone 3-phenylcarboxamide analogs were previously identified as novel potent and reversible inhibitors of human MAO-B (with essentially no activity on MAO-A). ${ }^{13}$ As their exact mechanism of enzyme inhibition was not clarified and no experimental structural information was available, we carried out a crystallographic and biochemical analysis of selected chromone analogs (Figure 2). Our studies showed that chromone inhibitors bind in the enzyme active site cavity with the 1,4-benzopyrone moiety ring in front of the flavin cofactor and they establish two hydrogen bonds with Tyr435 and Cys 172 (Figures 3b, 3c, 3d). The position of the substituted exocyclic ring is also well conserved for all three chromone analogs, with the halogen atoms of $\mathbf{2}$ and $\mathbf{3}$ overlapping with one of the two methyl groups of $\mathbf{1}$ and with the fluorine atom of safinamide (Figure 4). The planar conformation of these inhibitors, enhanced by an 
intramolecular hydrogen bond between the pyrone carbonyl group and the amide spacer, perfectly fits the flat hydrophobic active site cavity of human MAO-B. These results are in agreement with most of previous docking predictions, ${ }^{11,}{ }^{14}$ and were interpreted in light of the tight-binding inhibition mode of these chromone analogs. As a matter of fact, the steady-state inhibition studies resulting in either mixed or non-competitive inhibition profiles (confirmed also with the purified recombinant enzyme) were in contrast with what observed in the crystal structures. Accordingly, a dose-response curve approach $^{21}$ was adopted, which clearly revealed that chromone analogs are tightbinding inhibitors with $K_{i}$ values of 55, 17 and $31 \mathrm{nM}$ for 1, 2 and 3, respectively. Although it is known that the chromone moiety itself displays a high affinity for MAOB active site, we postulate that the hydrogen bond provided by the spacer carbonyl to Cys 172 and the perfect match of the whole molecule of these analogs with the enzyme cavity significantly enhance their inhibitory activity. Remarkably, this was also observed in the cellular context with a 1000-fold stronger reduction of ROS levels in treated HEK-293 cells for both 1 and $\mathbf{2}$ compared to the well-known covalent MAO-B inhibitor $L$-deprenyl. In conclusion, the chromone core represents a valuable scaffold for the development of novel potent and reversible inhibitors of human MAO-B.

\section{Experimental section}

Reagents. Chromone-3-carboxylic acid, 3-formylchromone, sodium sulphate, dimethylformamide (DMF), phosphorus oxychloride $\left(\mathrm{POCl}_{3}\right)$, aniline derivatives were purchased from Sigma-Aldrich. All other reagents and solvents were pro analysis grade and were acquired from Carlo Erba Reagents and Scharlab and were used without additional purification. All reagents for protein purification and crystallization and for 
enzymatic assays were purchased from Sigma-Aldrich, except for detergents that were from Anatrace (USA).

General procedures. Thin-layer chromatography (TLC) was carried out on precoated silica gel 60 F254 (Merck) with layer thickness of $0.2 \mathrm{~mm}$. For analytical control the following systems were used: ethyl acetate/methanol and chloroform/methanol in several proportions. The spots were visualized under UV detection (254 and $366 \mathrm{~nm}$ ). Flash chromatography was performed using silica gel $600.2-0.5$ or $0.040-0.063 \mathrm{~mm}$ (Carlo Erba Reagents). Following the workup, the organic phases were dried over $\mathrm{Na}_{2} \mathrm{SO}_{4}$. Solutions were decolorized with activated charcoal, when necessary. The recrystallization solvents were ethyl acetate, dichloromethane or ethyl ether/n-hexane. Solvents were evaporated in a Buchi Rotavapor. The purity of the final products $(>97 \%$ purity) was verified by high-performance liquid chromatography (HPLC) equipped with a UV detector. Chromatograms were obtained in an HPLC/DAD system, a Jasco instrument (pumps model 880-PU and solvent mixing model 880-30, Tokyo, Japan), equipped with a commercially prepacked Nucleosil RP-18 analytical column (250 mm x $4.6 \mathrm{~mm}, 5 \mu \mathrm{m}$, Macherey-Nagel, Duren, Germany), and UV detection (Jasco model $875-\mathrm{UV})$ at the maximum wavelength of $254 \mathrm{~nm}$. The mobile phase consisted of a methanol/water or acetonitrile/water (gradient mode, room temperature) at a flow rate of $1 \mathrm{~mL} / \mathrm{min}$. The chromatographic data was processed in a Compaq computer, fitted with CSW 1.7 software (DataApex, Czech Republic). NMR data were acquired, at room temperature, on a Brüker AMX 400 spectrometer operating at $400.15 \mathrm{MHz}$ for ${ }^{1} \mathrm{H}$ and 100.62 $\mathrm{MHz}$ for ${ }^{13} \mathrm{C}$. Chemical shifts were expressed in $\delta(\mathrm{ppm})$ values relative to tetramethylsilane (TMS) as internal reference; coupling constants $(J)$ were given in $\mathrm{Hz}$. Assignments were also made from DEPT (Distortionless Enhancement by Polarization 
Transfer) (underlined values). Mass spectra (MS) were carried out on a Bruker Microtof (ESI) apparatus; the data were reported as $\mathrm{m} / z$ ( $\%$ of relative intensity of the most important fragments).

Synthesis of chromone carboxamides (1-3). To a solution of chromone-3-carboxylic acid $(2.6 \mathrm{mmol})$ in $\mathrm{DMF}(4 \mathrm{~mL}), \mathrm{POCl}_{3}(2.6 \mathrm{mmol})$ was added. The mixture was stirred at room temperature for $30 \mathrm{~min}$ for the in situ formation of the acyl chloride. Then, an aromatic amine with the desired aromatic pattern was added to the reaction. After 1-5 hours, the mixture was diluted with dichloromethane $(20 \mathrm{~mL})$, washed with $\mathrm{H}_{2} \mathrm{O}(2 \times 10$ $\mathrm{mL})$ and with saturated $\mathrm{NaHCO}_{3}$ solution $(2 \times 10 \mathrm{~mL})$. The organic phase was dried, filtered and concentrated under reduced pressure. The crude product was purified by flash chromatography and/or crystallization.

$N$-(3'-Fluorophenyl)-4-oxo-4H-chromene-3-carboxamide (3). The compound was obtained in $40 \%$ yield and recrystallized from $\mathrm{CH}_{2} \mathrm{Cl}_{2} .{ }^{1} \mathrm{H} \mathrm{NMR}(400 \mathrm{MHz}, \mathrm{CDCl} 3) \delta$ $11.51(1 \mathrm{H}, s, \mathrm{NH}), 9.07(1 \mathrm{H}, s, \mathrm{H} 2), 8.34(1 \mathrm{H}, d d, \mathrm{~J}=8.0,1.3 \mathrm{~Hz}, \mathrm{H} 5), 7.80(1 \mathrm{H}, d d, \mathrm{~J}$ $\left.=2.0,2.0 \mathrm{~Hz}, \mathrm{H} 2^{\prime}\right), 7.72(1 \mathrm{H}, d d d, J=8.7,7.1,1.7 \mathrm{~Hz}, \mathrm{H} 7), 7.63-7.52(2 \mathrm{H}, m, \mathrm{H} 8$, H6), 7.39 - 7.24 (2H, $m$, H6', H5'), 6.84 (1H, ddd, J = 8.0, 2.1, 0.9 Hz, H4'). ${ }^{13} \mathrm{C}$ NMR $\left(101 \mathrm{MHz}, \mathrm{CDCl}_{3}\right) \delta 177.4 \mathrm{C} 4,164.2 \mathrm{C} 3$ ', $\underline{163.0} \mathrm{C} 2,160.9 \mathrm{CONH}, 156.2 \mathrm{C} 8 \mathrm{a}, 139.4$ C1', 135.0 C7, 130.1 C5', 126.6 C5, 126.3 C6, 124.0 C4a, 118.6 C6', 115.9 C2', 115.8 C8, 111.3 C4', 111.0 C3. ESI/MS m/z (\%): $283\left(\mathrm{M}^{+}+\mathrm{Na}^{+}, 100\right)$.

Synthesis of 3-(((3-chlorophenyl)amino)methyl)-4H-chromen-4-one (4). To a solution of 3-formylchromone $(250 \mathrm{mg}, 1.4 \mathrm{mmol})$ in dichloromethane $(5 \mathrm{~mL}), 3$ chloroaniline $(154 \mathrm{mg}, 1.4 \mathrm{mmol})$ and $\mathrm{Na}(\mathrm{AcO})_{3} \mathrm{BH}(426 \mathrm{mg}, 2 \mathrm{mmol})$ were added 
under inert atmosphere at room temperature. After 15 minutes, the mixture was diluted with $\mathrm{CH}_{2} \mathrm{Cl}_{2}(40 \mathrm{~mL})$ and washed with saturated $\mathrm{NaHCO}_{3}$ solution $(2 \times 10 \mathrm{~mL})$. The organic phase was dried, filtered and evaporated. The residue was purified by flash chromatography $\left(\mathrm{CH}_{2} \mathrm{Cl}_{2}\right)$. The compound was obtained in $60 \%$ yield and recrystallized from $\mathrm{CH}_{2} \mathrm{Cl}_{2} .{ }^{1} \mathrm{H}$ NMR (400 MHz, $\left.\left.\mathrm{CDCl}_{3}\right) \delta 8.23(1 \mathrm{H}, d d d, \mathrm{~J}=8.0,1.7,0.4 \mathrm{~Hz}, \mathrm{H} 5)\right)$, $7.91(1 \mathrm{H}, t, \mathrm{~J}=1.0 \mathrm{~Hz}, \mathrm{H} 2), 7.67(1 \mathrm{H}, d d d, \mathrm{~J}=8.6,7.1,1.7 \mathrm{~Hz}, \mathrm{H} 7), 7.48-7.35(2 \mathrm{H}$, $m, \mathrm{H} 6, \mathrm{H} 8), 7.06\left(1 \mathrm{H}, d d, \mathrm{~J}=8.0,8.0 \mathrm{~Hz}, \mathrm{H} 5^{\prime}\right), 6.68(1 \mathrm{H}, d d d, \mathrm{~J}=8.0,2.1,0.9 \mathrm{~Hz}$, H4'), $6.63\left(1 \mathrm{H}, d d, \mathrm{~J}=2.1,2.1 \mathrm{~Hz}, \mathrm{H} 2^{\prime}\right), 6.52(1 \mathrm{H}, d d d, \mathrm{~J}=8.2,2.0,0.9 \mathrm{~Hz}, \mathrm{H} 6$ '), 4.24 $\left(2 \mathrm{H}, d, \mathrm{~J}=1.0 \mathrm{~Hz}, \mathrm{CH}_{2}\right) \cdot{ }^{13} \mathrm{C} \mathrm{NMR}\left(101 \mathrm{MHz}, \mathrm{CDCl}_{3}\right) \delta 177.9 \mathrm{C} 4,156.6 \mathrm{C} 8 \mathrm{a}, \underline{153.1} \mathrm{C} 2$, 148.6 C1', 135.1 C3', 133.8 C7, 130.3 C5, $\underline{125.7}$ C6, 125.3 C4', 123.8 C4a, 120.8 C3, $\underline{118.2} \mathrm{C}^{\prime}, \underline{118.0} \mathrm{C} 8, \underline{113.1} \mathrm{C}^{\prime}, 111.8 \mathrm{C} 6$ ', $\underline{40.4} \mathrm{CH}_{2} . \mathrm{ESI} / \mathrm{MS} \mathrm{m} / \mathrm{z}(\%): 285\left(\mathrm{M}^{+}+1\right.$, 20), 159 (96), $131(100)$.

Enzymatic assays. Human recombinant MAO-A and MAO-B were expressed in Pichia pastoris and purified as described. ${ }^{23,}{ }^{24}$ Purified protein samples were stored in $50 \mathrm{mM}$ potassium phosphate buffer $\mathrm{pH} 7.5,0.8 \%$ (w/v) $\beta$-octylglucoside, $20 \%$ glycerol. Enzyme concentration was determined by measuring the absorbance UV/Vis spectrum using a NanoDrop ND-1000 spectrophotometer (Thermo Scientific). MAO-A and MAO-B activity was determined by a fluorescence-based method with benzylamine and kynuramine as substrates, respectively, which detects the increase in $\mathrm{H}_{2} \mathrm{O}_{2}$ (side-product of the MAO reaction) with time using the horseradish peroxidase-Amplex Red coupled assay. ${ }^{20}$ All measurements were done in in $50 \mathrm{mM}$ Hepes buffer, $\mathrm{pH} 7.5$, containing $0.25 \%(\mathrm{w} / \mathrm{v})$ reduced Triton $\mathrm{X}-100$ at $25{ }^{\circ} \mathrm{C}$ using either a CLARIOstar plate reader (BMG Labtech) or a Cary Eclipse fluorimeter (Agilent) depending on the type of experiment. 
Steady-state kinetic analysis. The chromone analogs inhibition mechanism towards human MAO-B was determined by measuring the initial rates of substrate oxidation in the presence of varying concentrations of inhibitor. Data were fit to the appropriate form of the Michaelis-Menten equation and analyzed using GraphPad Prism software 5.0. The mode of inhibition was determined using global fit analysis of the enzyme velocity versus substrate concentration curves in the presence and absence of the inhibitor to equations for competitive, mixed, non-competitive, and uncompetitive inhibition. Visual inspection of the fitting curves and evaluation of the $r^{2}$ value were used to select the best fitting for determination of the inhibition constants. The results were also analyzed as double reciprocal plots (1/k $\mathrm{k}_{\text {cat }}$ Vs. $\left.1 /[\mathrm{S}]\right)$.

Tight-binding inhibition assays and $K_{i}$ determination. Further inhibition studies were carried out using the same fluorescence-based assay described above following protocols developed for tight-binding inhibition ${ }^{18}$. In particular, the tight-binding inhibition mechanism for each chromone analog was evaluated by measuring the $\mathrm{IC}_{50}$ values (obtained by fitting percentage of inhibition data versus inhibitor concentration using GraphPad software 5.0) at four fixed substrate concentrations and plotting these values versus substrate concentration. Next, $K i$ values were determined through a doseresponse curve by plotting the enzyme activity values at a fixed substrate concentration (2.7 $\mathrm{mM}$ benzylamine) and at varying concentrations of each chromone inhibitor using the Morrison equation ${ }^{25}$ in GraphPad Prism software 5.0.

X-ray crystallography. Human MAO-B in $50 \mathrm{mM}$ potassium phosphate $\mathrm{pH} 7.5,8.5$ $\mathrm{mM}$ Zwittergent 3-12 was co-crystallized with the investigated inhibitors by the sitting- 
drop vapour diffusion method following published protocols. ${ }^{19}$ X-ray diffraction data were collected at the beamlines of the Swiss Light Source in Villigen (Switzerland) and European Synchrotron Radiation Facility in Grenoble (France). For data collection, crystals were transferred into a mother liquor solution containing $18 \%(\mathrm{v} / \mathrm{v})$ glycerol and flash-cooled in a stream of gaseous nitrogen at $100 \mathrm{~K}$. Data processing and scaling (Table 1) were performed using $\mathrm{XDS}^{26}$ and the CCP4 package. ${ }^{27}$ The coordinates of the MAO B-safinamide complex, ${ }^{15}$ deprived of all water and inhibitor atoms, were used as initial model. The program $\operatorname{Coot}^{28}$ was used for electron density inspection and model building, whereas crystallographic refinement was performed with the program REFMAC5. ${ }^{29}$ Figures were generated by the program CCP4mg. ${ }^{30}$

\section{Biological evaluation of ROS production.}

HEK-293 cells were grown in DMEM containing 10\% heat-inactivated FBS under 5\% $\mathrm{CO} 2$ at $37^{\circ} \mathrm{C}$. Cells were transfected with the plasmid pcDNA3.1-MAO-B (rat cDNA) using Lipofectamine (Thermo Fisher scientific). Tyramine and L-deprenyl were from Sigma-Aldrich. Intracellular ROS were measured using the DCFDA probe assay (Thermo Fisher Scientific). Briefly, cells were loaded for 45 minutes with DCFDA probe $(5 \mu \mathrm{M})$, washed with HBSS and stimulated with tyramine $(500 \mu \mathrm{M})$ in HBSS for $15 \mathrm{~min}$, in the presence of the indicated inhibitors. Fluorescence was measured using Varioskan microplate reader (Thermo Fisher Scientific).

\section{PDB ID Codes}

Authors will release the atomic coordinates and experimental data upon article publication. 


\section{AUTHOR INFORMATION}

\section{Corresponding Author}

*E-mail: claudia.binda@unipv.it. Phone: (+39)0382-985527.

\section{Funding Sources}

This work was supported by Fondazione Cariplo (grant n. 2014-0672 to C.B.), Foundation for Science and Technology (FCT), FEDER/COMPETE2020 (UID/QUI/00081/2015 and POCI-01-0145-FEDER-006980).

\section{Notes}

The authors declare no competing financial interest.

\section{ACKNOWLEDGMENT}

Fellowships for J.R. (SFRH/BD/96033/2013) and F.C. (SFRH/BPD/74491/2010) are supported by FCT and FEDER/COMPETE funds. N.M.'s post-doc fellowship was supported by Fondazione Cariplo (grant n. 2014-0672 to C.B.). The COST action CA15135 (Multi-target paradigm for innovative ligand identification in the drug discovery process MuTaLig) and Società Italiana di Biofisica e Biologia Molecolare (SIBBM) are kindly acknowledged for supporting visiting fellowships to J.R. We thank the European Synchrotron Radiation Facility (ESRF) and the Swiss Light Source (SLS) for providing beamtime and assistance and the European Community's Seventh Framework Programme (FP7/2007-2013) under BioStruct-X (Grants 7551 and 10205) for funding synchrotron trips. JMP and AP were founded by Région Occitanie. 


\section{ABBREVIATIONS}

MAO-A, monoamine oxidase A; MAO-B, monoamine oxidase B; FAD, flavin adenine dinucleotide; CNS, central nervous system; MD, molecular dynamics; ROS, reactive oxygen species; DMF, $N, N$-dimethylformamide.

\section{REFERENCES}

1. Edmondson, D. E.; Binda, C.; Wang, J.; Upadhyay, A. K.; Mattevi, A. Molecular and Mechanistic Properties of the Membrane-Bound Mitochondrial Monoamine Oxidases. Biochemistry 2009, 48, 4220-4230.

2. Rona, R. R. Monoamine Oxidases: The Biochemistry of the Proteins As Targets in Medicinal Chemistry and Drug Discovery. Curr. Top. Med. Chem. 2012, 12, 21892209.

3. Blair, H. A.; Dhillon, S. Safinamide: A Review in Parkinson's Disease. CNS Drugs 2017, 31, 169-176.

4. de la Fuente-Fernández, R.; Sossi, V.; Huang, Z.; Furtado, S.; Lu, J.-Q.; Calne, D. B.; Ruth, T. J.; Stoessl, A. J. Levodopa-induced changes in synaptic dopamine levels increase with progression of Parkinson's disease: implications for dyskinesias. Brain 2004, $127,2747-2754$.

5. Maggiorani, D.; Manzella, N.; Edmondson, D. E.; Mattevi, A.; Parini, A.; Binda, C.; Mialet-Perez, J. Monoamine Oxidases, Oxidative Stress, and Altered Mitochondrial Dynamics in Cardiac Ageing. Oxid. Med. Cell. Longev. 2017, 2017, 3017947.

6. Wu, J. B.; Yin, L.; Shi, C.; Li, Q.; Duan, P.; Huang, J.-M.; Liu, C.; Wang, F.; Lewis, M.; Wang, Y.; Lin, T.-P.; Pan, C.-C.; Posadas, E. M.; Zhau, H. E.; Chung, L. W. K. MAOA-Dependent Activation of Shh-IL6-RANKL Signaling Network Promotes 
Prostate Cancer Metastasis by Engaging Tumor-Stromal Cell Interactions. Cancer Cell. 2017, 31, 368-382.

7. Czech, M. P. Macrophages dispose of catecholamines in adipose tissue. Nat. Med. 2017, 23, 1255.

8. Gaspar, A.; Matos, M. J.; Garrido, J.; Uriarte, E.; Borges, F. Chromone: A Valid Scaffold in Medicinal Chemistry. Chem. Rev. 2014, 114, 4960-4992.

9. Reis, J.; Gaspar, A.; Milhazes, N.; Borges, F. Chromone as a Privileged Scaffold in Drug Discovery: Recent Advances. J. Med. Chem. 2017, 60, 7941-7957.

10. Gaspar, A.; Reis, J.; Fonseca, A.; Milhazes, N.; Viña, D.; Uriarte, E.; Borges, F. Chromone 3-phenylcarboxamides as potent and selective MAO-B inhibitors. Bioorg. Med. Chem. Lett. 2011, 21, 707-709.

11. Gaspar, A.; Silva, T.; Yáñez, M.; Vina, D.; Orallo, F.; Ortuso, F.; Uriarte, E.; Alcaro, S.; Borges, F. Chromone, a Privileged Scaffold for the Development of Monoamine Oxidase Inhibitors. J. Med. Chem. 2011, 54, 5165-5173.

12. Cagide, F.; Silva, T.; Reis, J.; Gaspar, A.; Borges, F.; Gomes, L. R.; Low, J. N. Discovery of two new classes of potent monoamine oxidase-B inhibitors by tricky chemistry. Chem. Comm. 2015, 51, 2832-2835.

13. Reis, J.; Cagide, F.; Chavarria, D.; Silva, T.; Fernandes, C.; Gaspar, A.; Uriarte, E.; Remiao, F.; Alcaro, S.; Ortuso, F.; Borges, F. Discovery of New Chemical Entities for Old Targets: Insights on the Lead Optimization of Chromone-Based Monoamine Oxidase B (MAO-B) Inhibitors. J. Med. Chem. 2016, 59, 5879-5893.

14. Giulio, F.; Santiago, V.; Maria, J. M.; Eugenio, U.; Enzo, C. Monoamine Oxidase Inhibitors: Ten Years of Docking Studies. Curr. Top. Med. Chem. 2012, 12, 2145-2162. 
15. Binda, C.; Wang, J.; Pisani, L.; Caccia, C.; Carotti, A.; Salvati, P.; Edmondson,

D. E.; Mattevi, A. Structures of Human Monoamine Oxidase B Complexes with Selective Noncovalent Inhibitors: Safinamide and Coumarin Analogs. J. Med. Chem. 2007, 50, 5848-5852.

16. Mazmanian, K.; Sargsyan, K.; Grauffel, C.; Dudev, T.; Lim, C. Preferred Hydrogen-Bonding Partners of Cysteine: Implications for Regulating Cys Functions. $J$. Phys. Chem. B 2016, 120, 10288-10296.

17. Echols, N.; Moriarty, N. W.; Klei, H. E.; Afonine, P. V.; Bunkóczi, G.; Headd, J. J.; McCoy, A. J.; Oeffner, R. D.; Read, R. J.; Terwilliger, T. C.; Adams, P. D. Automating crystallographic structure solution and refinement of protein-ligand complexes. Acta Crystallogr. D 2014, 70, 144-154.

18. Li, M.; Binda, C.; Mattevi, A.; Edmondson, D. E. Functional Role of the "Aromatic Cage" in Human Monoamine Oxidase B: Structures and Catalytic Properties of Tyr435 Mutant Proteins. Biochemistry 2006, 45, 4775-4784.

19. Binda, C.; Hubálek, F.; Li, M.; Herzig, Y.; Sterling, J.; Edmondson, D. E.; Mattevi, A. Crystal Structures of Monoamine Oxidase B in Complex with Four Inhibitors of the N-Propargylaminoindan Class. J. Med. Chem. 2004, 47, 1767-1774.

20. Zhou, M.; Panchuk-Voloshina, N. A One-Step Fluorometric Method for the Continuous Measurement of Monoamine Oxidase Activity. Anal. Biochem. 1997, 253, 169-174.

21. Copeland, R. A. Tight Binding Inhibitors. In Enzymes: A Practical Introduction to Structure, Mechanism, and Data Analysis, 2nd ed.; Wiley-VCH, Inc: 2000; pp 304317.

22. Cha, S.; Agarwal, R. P.; Parks, R. E. Tight-binding inhibitors-II: Non-steady state nature of inhibition of milk xanthine oxidase by allopurinol and alloxanthine and 
of human erythrocytic adenosine deaminase by coformycin. Biochem. Pharmacol. 1975, 24, 2187-2197.

23. Li, M.; Hubálek, F. e.; Newton-Vinson, P.; Edmondson, D. E. High-Level Expression of Human Liver Monoamine Oxidase A in Pichia pastoris: Comparison with the Enzyme Expressed in Saccharomyces cerevisiae. Protein Expr. Purif. 2002, 24, $152-162$.

24. Newton-Vinson, P.; Hubalek, F.; Edmondson, D. E. High-Level Expression of Human Liver Monoamine Oxidase B in Pichia pastoris. Protein Expr. Purif. 2000, 20, $334-345$

25. Henderson, P. J. F. A linear equation that describes the steady-state kinetics of enzymes and subcellular particles interacting with tightly bound inhibitors. Biochem. $J$. 1972, 127,321

26. Kabsch, W. XDS. Acta Crystallogr. D 2010, 66, 125-132.

27. Collaborative Computational Project, N. The CCP4 Suite: Programs for protein Crystallography. Acta Crystallogr 1994, D50, 760-767.

28. Emsley, P.; Lohkamp, B.; Scott, W. G.; Cowtan, K. Features and development of Coot. Acta Crystallogr. D 2010, 66, 486-501.

29. Murshudov, G. N.; Skubak, P.; Lebedev, A. A.; Pannu, N. S.; Steiner, R. A.; Nicholls, R. A.; Winn, M. D.; Long, F.; Vagin, A. A. REFMAC5 for the refinement of macromolecular crystal structures. Acta Crystallogr. D 2011, 67, 355-367.

30. McNicholas, S.; Potterton, E.; Wilson, K. S.; Noble, M. E. M. Presenting your structures: the CCP4mg molecular-graphics software. Acta Crystallogr. D 2011, 67, 386-394. 
Table 1. Data collection and refinement statistics for the crystal structures of human MAO B in complex with chromone inhibitors.

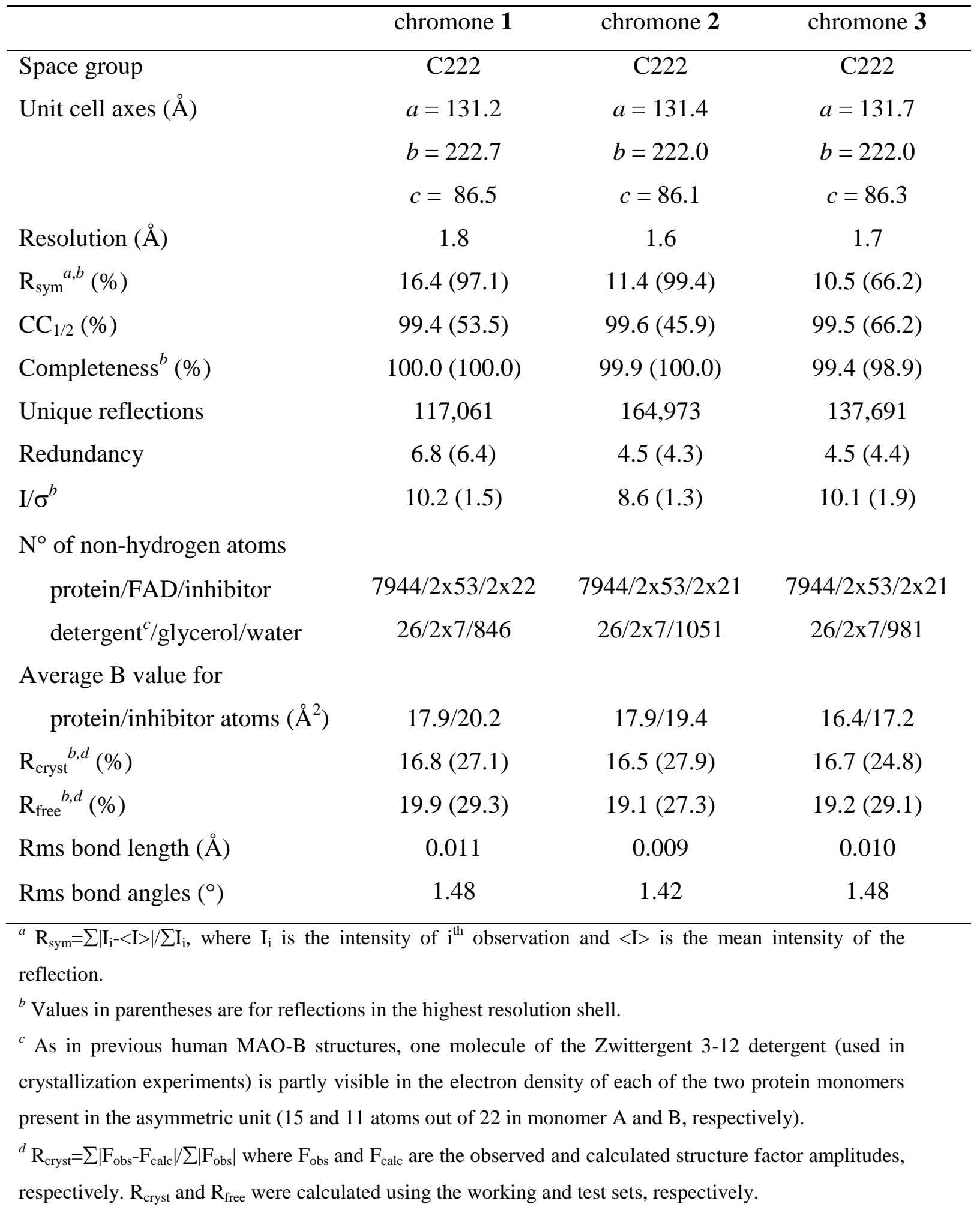


